\title{
Labor market policies and European crises
}

\author{
Giuseppe Bertola
}

\section{Correspondence:}

giuseppe.bertola@edhec.edu EDHEC Business School, 393

Promenade des Anglais, Nice, France

\begin{abstract}
This paper studies theoretically and empirically why and how labor policies may reduce productivity and employment in order to stabilize labor incomes and redistribute resources. It proposes a specific stylized model where the tradeoffs facing labor policies are influenced by structural factors, inspects the empirical relevance of this mechanism in European data, and outlines the proposed theoretical perspective's implications for reform design in crisis-hit economies.
\end{abstract}

JEL codes: D78; J38

Keywords: Uninsurable risk; Productivity; Economic integration

\section{Introduction}

Labor market reforms could significantly increase productivity and speed up growth in Europe, especially if accompanied by product market reforms (see e.g. Barkbu et al., 2012, and its references). If such reforms were unambiguously beneficial, however, they would be obvious free lunches, unlikely to remain unexploited until discovered by economists.

Economic research can more plausibly help policy-makers by analyzing how the structural and political characteristics of different countries and periods shape trade-offs between productivity and other objectives. Yet, such arguments are not often spelled out explicitly by advocates of reforms, who sometimes seem to fight a previous war, praising policy frameworks that perform well in specific instances (such as Danish flexicurity in times of growth and structural transformation, or German vocational education in the current crisis) without characterizing clearly how past policy choices relate to various aspects of subsequent performance. In reality, markets are not as perfect as economists would like them to be, policy-makers are not as powerful as they would like to be, and policies that trade production efficiency off labor income stability have different implications for the welfare of different individuals. Hence, no labor market configuration is optimal in all circumstances and from all points of view, and a positive theory of labor policy needs to take into account its implications in terms of distribution as well as of production efficiency.

This paper illustrates the policy-choice and empirical implications of this perspective using a model, set up in Section 2, of an economy where policy provides protection from uninsurable labor income shocks and reduces individual incentives to perform costly actions that increase aggregate production. Section 3 outlines how this and more general models can help interpret labor policy choices and effects in terms not only of risk aversion, but also of distributional tensions and international market pressure. Section 4

(O2014 Bertola; licensee Springer. This is an Open Access article distributed under the terms of the Creative Commons Attribution License (http://creativecommons.org/licenses/by/2.0), which permits unrestricted use, distribution, and reproduction in any medium, provided the original work is properly cited. 
examines European empirical evidence from that perspective. Section 5 discusses the possible role of labor policies in the path towards the eurozone crisis, and the credibility problems faced by crisis-triggered reforms of labor policies that are meant to protect individuals from risk and have delayed productivity effects. Section 6 concludes with some more general considerations.

\section{A model}

In reality, productivity differs across similar workers because some of them choose to perform effort or human capital investments that entail a cost and should be compensated by higher earnings, and also because random shocks make individual earnings deviate ex post from those that could be expected at the time when that choice was made. To model this crucial feature of the environment in which labor policies are implemented, let labor earnings (gross of any tax or subsidy) be

$$
w_{1}=\alpha_{1}-\beta l+v_{1}
$$

for labor units that pay a cost $k$ before realization of a random zero-mean shock $v_{1}$, and

$$
w_{2}=\alpha_{2}-\beta(1-l)+v_{2}
$$

for those that do not, where $v_{2}$ is an independent and possibly differently distributed shock. The expectation of earnings corresponds to marginal productivity, which for $\beta>0$ decreases in the fraction $l$ of the labor force that chooses the costly option of drawing earnings from (1). As $l$ increases above zero, expected earnings increase in (1) and fall in (2), and when $0<\alpha_{2}<\alpha_{1}$ they cross at at a value of $l$ larger than half: to maximize expected production, more labor should be allocated to the jobs that pay according to (1) rather than to those that pay according to (2).

Realistic financial markets imperfections make it difficult to shelter consumption from income shocks, and imply that a risk-averse individual's welfare increases in expected income and decreases in income variability. To formalize this simply, let the shocks be normally distributed, $v_{1} \sim N\left(0, \sigma_{1}^{2}\right)$ and $v_{2} \sim N\left(0, \sigma_{2}^{2}\right)$; let utility have the constant absolute risk aversion form $u(c)=-\exp (-v c)$; and suppose that $c=y+a$, where $y$ is disposable labor income and $a$ denotes other resources on which individual consumption can draw. Recalling that when $z \sim N\left(\mu, \sigma^{2}\right)$ then $-E[\exp (-v z)]=-\exp \left(-v \mu+\frac{1}{2} v^{2} \sigma^{2}\right)$, expected utility is an increasing function of

$$
V=E[y+a]-\frac{v}{2} \operatorname{var}[y+a]
$$

and non-labor income $a$ is conveniently irrelevant to the choice between paying $k$ to earn $w_{1}$ from (1), or earning $w_{2}$ from (2).

In the economy's laissez faire equilibrium, $y$ equals earnings. To model the difficulty of disentangling choices and luck as determinants of labor income, let it be impossible to ascertain whether it is drawn from (1) or from (2), representing the more basic assumption that (as is appropriate for e.g. effort) the costly action that determines the mean and variance of earnings is not observable. And consider the implications of funding a per capita subsidy $s$ by taxing observed earnings, at some constant rate $\tau$ for simplicity (a more sophisticated taxation scheme could take into account that large realizations are 
more likely to be drawn from a higher-mean distribution, with similar qualitative implications as long as luck plays a significant role in determining individual labor income and consumption).

In equilibrium, the interior fraction of the labor market's identical individuals that chooses each of the employment opportunities (1) and (2) should be such as to make them all be indifferent between paying $k$ and earning $y_{1}=(1-\tau) w_{1}+s$, or earning $y_{2}=(1-\tau) w_{2}+s$. Using $E\left[y_{1}\right]=(1-\tau)\left(\alpha_{1}-\beta_{1} l\right), \operatorname{var}\left[y_{1}\right]=(1-\tau)^{2} \sigma_{1}^{2}$, $E\left[y_{2}\right]=(1-\tau)\left(\alpha_{2}-\beta_{2}(1-l)\right)$, and $\operatorname{var}\left[y_{2}\right]=(1-\tau)^{2} \sigma_{2}^{2}$ in (3), indifference obtains when

$$
l(\tau)=\left(\frac{1}{2}+\frac{1}{2 \beta}\left(\alpha_{1}-\alpha_{2}-\left(\frac{k}{1-\tau}+\frac{\nu}{2}(1-\tau)\left(\sigma_{1}^{2}-\sigma_{2}^{2}\right)\right)\right)\right):
$$

this labor allocation intuitively ensures that at the margin the net-of-tax expected earnings differentials equals the cost, in terms of risk as well as of investment or effort, of choosing (1).

Redistribution of random shocks is beneficial for risk-averse individuals but, by taxing expected earning differentials, reduces incentives to perform the costly actions that influence them as in (1) and (2). To assess the welfare implications of the redistribution policy indexed by $\tau$, it is necessary to account for the rents that in the model economy's structure are generated by decreasing returns to labor. Since labor compensation is based on decreasing marginal productivity, average production exceeds it by a per capita amount $\beta(0.5-l(\tau)(1-l(\tau)))$, which increases in $l(\tau)$ over the $0.5<l(\tau) \leq 1$ range spanned by the labor allocation choices (4), and is not random if individuals own well-diversified portfolios of production opportunities subject to idiosyncratic shocks.

The economy's average individual consumes per capita non-labor income as well as the risky net income of a unit of labor and the subsidy $s(\tau)=\left(l(\tau) w_{1}+(1-l(\tau)) w_{2}\right) \tau$. In equilibrium, that individual's welfare measure (3) is

$$
\begin{aligned}
V_{\mathrm{avg}}(\tau) & =\alpha_{1} l(\tau)-\frac{\beta}{2} l(\tau)^{2}+\alpha_{2}(1-l(\tau))-\frac{\beta}{2}(1-l(\tau))^{2} \\
& -k l(\tau)-\frac{\nu}{2}(1-\tau)^{2}\left(l(\tau) \sigma_{1}^{2}+(1-l(\tau)) \sigma_{2}^{2}\right) .
\end{aligned}
$$

This expressions quite intuitively subtracts from the economy's per capita output the investment cost, $k l(\tau)$, and the risk-aversion-weighted variance of per capita income and consumption. It depends on $\tau$ both directly, through the $(1-\tau)^{2}$ term, and through the $l(\tau)$ labor allocation function in (4).

In the model, the latter welfare effect of a larger $\tau$ is not necessarily negative. If $\sigma_{1}^{2}>\sigma_{2}^{2}$, allocating labor to the earning opportunities (1) is costly in terms of additional ex-post risk. In this case, redistribution of ex post income shocks internalizes to individual choices the average production effects of labor allocation to employment opportunities that, while more productive on average, entail more idiosyncratic risk, and a social safety net can, as in Sinn (1996) or Andersen (2010), improve risk-taking incentives and increase average production at the same time as it reduces consumption risk. The derivative of the expression in (4) is positive at $\tau=0$ if $v\left(\sigma_{1}^{2}-\sigma_{2}^{2}\right) / 2>k$, i.e., if in laissez fair uninsurable idiosyncratic risk is the main reason why labor is not allocated to more productive uses. In this case, redistribution is unambiguously beneficial. Since policy-makers 
need not always be able to identify such Pareto improvements, it would not be surprising to find that in some cases more intrusive labor policies would increase productive efficiency.

The model has more interesting implications when $k>0$ implies a trade-off between average production and income security. Since the term $-k /(1-\tau)$ grows exponentially more negative in the (4) expression for equilibrium allocation as $\tau$ increases towards unity, any positive effect of the $\sigma_{1}^{2}-\sigma_{2}^{2}$ risk differential cannot make full redistribution optimal. In the model, and in real-life situations where luck and choice cannot be disentangled in observed labor incomes, larger values of $\tau$ on the one hand eliminate expected earnings differentials, reduce incentives to perform ex ante investment, and make the economy's labor market increasingly sclerotic and unproductive; on the other hand, they smooth out uninsurable income shocks, and through this channel increase the welfare of risk-averse individuals.

For an individual who is entitled to the economy's per capita income and suffers the idiosyncratic risk that policy does not smooth out, as long as $v>0$ implies risk aversion welfare increases in $\tau$ beyond the point where any positive output effects are exhausted, and begins to fall when the first order condition for maximization of (5) holds. The model yields an explicit expression for that optimal tax rate, which is too cumbersome to be shown but intuitively indicates that larger values of $v$ and $\sigma_{1}$ strengthen the benefits of risk reduction, as in Mirrlees (1971), Okun (1975), and other classic studies of incentive-compatible social insurance schemes. The implications of model's marginal productivity slope are perhaps less familiar, and can be established by standard comparative statics methods. Totally differentiating the first order condition $\partial V(\tau, \beta) / \partial \tau=0$ for maximization of the typical individual's welfare,

$$
\frac{d \tau^{*}}{d \beta}=\frac{\partial V(\tau, \beta)}{\partial \beta \partial \tau} /\left(-\frac{\partial^{2} V\left(\tau^{*}, \beta\right)}{\partial \tau^{2}}\right)
$$

The denominator is positive by the second order condition for a maximum of $V(\tau,$.$) ,$ differentiating (5) yields $\partial V(\tau, \beta) / \partial \beta=-0.5+l(1-l)$, and the expression in (6) has the same sign as

$$
\frac{d}{d \tau} l(\tau)(1-l(\tau))=\left(1-2 l\left(\tau^{*}\right)\right) l^{\prime}\left(\tau^{*}\right)
$$

which is negative for $l\left(\tau^{*}\right)>0.5$ and $l^{\prime}\left(\tau^{*}\right)<0$.

When productivity and earnings depend more strongly on labor allocation (in the model, when $\beta$ is larger), then the optimal intensity of redistribution is lower (in the model, $\tau^{*}$ is smaller). Intuitively, redistribution is appealing because it smooths uninsurable income shocks, but has more negative side effects in terms of average production when production depends more strongly on individual incentives to perform costly investment or effort.

\section{From the model to reality}

The model illustrates the motivation and effects of income redistribution across jobs or occupations that require different ex ante effort or investment, and may entail different ex post risk. Simple modeling variations can have qualitatively similar implications for the 
employment and unemployment effects of other policies that are also meant to isolate the welfare of workers from uninsurable shocks, with production-efficiency side effects. To model employment taxes that fund unemployment or retirement benefits, the earnings denoted $w_{2}$ in the model could be reinterpreted as the income-term flow welfare of leisure or informal work (there should then be constant rather than decreasing returns, or perhaps rents could accrue directly to individuals). In that setting, the employment and production effects of minimum wages or binding collective agreements would be similar to those of explicit tax and subsidy schemes, and their risk and inequality implications would depend on additional assumptions. More strictly binding lower bounds for the marginal productivity of formal employment would increase inequality if they draw a larger wedge between the incomes of employed and involuntarily unemployed individual. Wage bounds can however reduce earnings inequality if they imply wage compression (as in Agell, 2002), and reduce household income inequality if employed and unemployed individuals pool their labor incomes. Employment protection legislation is also harder to model formally but, as shown in e.g. Bertola (2004), has similar motivation and similar effects for productivity and earnings inequality. All these are "labor" policies (rather than more general tax policies) in that they redistribute work (or non-work) incomes, and influence incentives to perform costly actions that affect individual earnings as well as the economy's overall productivity.

Higher values of $\tau$ reduce the model economy's productivity and inequality (obviously in disposable income terms, and also in terms of gross earnings inasmuch as their distribution is more skewed but not more dispersed when fewer workers earn the more strongly differentiated wages needed to preserve investment incentives). Thus, for given model parameters variation of $\tau$ drives output and inequality in opposite directions, and implies a negative relationship between the average amount and the cross-sectional variance of income that is reminiscent of the classic Okun (1975) "equity vs. efficiency" trade-off. Since inequality across ex ante homogeneous individuals correspond to ex-ante risk, different values of $\tau$ determine the welfare-ranked outcomes discussed above for the economy's average individual. The form of the trade-off, and the point chosen along it by policy, depend on all of the model's parameters. For example, more uncertainty would imply that more intense redistribution is optimal, and lower productivity at the same time as ex post inequality increases (Mulligan, 2012). To interpret real-life variation of policy outcomes, however, it is important to recognize that observed production and inequality outcomes need not be those that maximize the total welfare of the economy. When financial markets are imperfect, welfare cannot be pooled, and the average individual is not as "representative" as if aggregate consumption could be transferred across real-life individuals.

If the static model were extended to allow each risk-averse individual to save rather than consume some of the labor income windfall shocks, it would be optimal to spread the consumption implications of labor income over multiple periods, and wealth and consumption inequality would increase over time (more widely when redistribution is mild, and without bounds when constant absolute risk aversion makes consumption levels irrelevant to consumption smoothing incentives as well as to labor allocation choices). In the model, all individuals are similarly endowed with labor and treated similarly by redistribution of ex post income, but since wealth inequality may naturally result from previous uninsurable labor income shocks, it is interesting to consider how the labor allocation and 
risk reduction effects of redistribution influence welfare of individuals entitled to different amounts of the economy's non-labor income.

For an individual who is entitled to income of a unit of labor (indifferently allocated to either sector) and to $\omega_{i}$ times the per capita amount of the other factors that produce the economy's output, welfare in the model is given by (5) plus $\omega_{i}-1$ times the amount $\beta\left(\frac{1}{2}-l(1-l)\right)$ of the economy's per capita non-labor income. The resulting expression has the same form as (5), with $\left(2-\omega_{i}\right) \beta$ replacing $\beta$. Intuitively, all labor units benefit equally from a reduction in labor income risk, but individuals entitled to different amounts of the economy's non-labor income are differently affected by redistribution's collateral damage in terms of production efficiency. Hence, if the politically decisive individual is entitled to a smaller-than-average $\omega_{i}<1$ portion of the economy's non-labor income, the policy-choice problem effectively features a smaller $\beta$ and, as shown when establishing the sign of expression (6), this implies a preference for more redistribution.

Consider next the implications for the policy-choice problem of allowing non-labor income to include not only rents (paid to exogenously given factors, such as land) but also payments to a factor (such as financial capital) that is perfectly elastically supplied at some unit income $\rho$. If the units of labor that pay $k$ work with an amount $K_{1}$ of the latter factor, a linear-quadratic production function can be written $\left(\alpha_{1}+\delta K_{1}\right) l-(\beta / 2) l^{2}-(\gamma / 2) K_{1}^{2}$. If the marginal productivity $\delta l-\gamma K_{1}$ of this additional factor must be equal to $\rho$, the expected marginal productivity component of the earnings (1) is $w_{1}=\alpha_{1}-\left(\beta-\delta^{2} / \gamma\right) l$. When the earnings (2) also correspond to labor's marginal productivity from $\left(\alpha_{2}+\delta K_{2}\right) l-$ $(\beta / 2) l^{2}-(\gamma / 2) K_{2}^{2}$ and $\delta l-\gamma K_{2}=\rho$, then welfare as a function of policy choice has the same form as (5), with a different intercept and slope $\beta-\delta^{2} / \gamma$. The beneficial uninsurable income smoothing effect of the tax is then traded off an output reduction effect that, with

$$
l^{\prime}(\tau)=-\frac{1}{2\left(\beta-\frac{\delta^{2}}{\gamma}\right)}\left(\frac{k}{(1-\tau)^{2}}-\frac{v}{2}\left(\sigma_{1}^{2}-\sigma_{2}^{2}\right)\right),
$$

is larger at each $\tau$ the larger is $\delta$, i.e. the more complementary to labor is $K$.

As $\delta$ grows larger, production reacts more strongly to redistribution. Hence, a smaller $\tau$ maximizes the welfare any individual indexed by $i$ obtains from a unit of labor, a portion $\omega_{i}$ of the per capita rents that decreasing returns allow after $K$ and labor are paid their marginal productivity, and income $\rho K_{i}$ drawn from factors that are perfectly elastically supplied, hence immune from tax incidence. While the identity of the decisive individual of course depends on political institutions (and does not generally coincide with the average individual when financial markets are imperfect), the model illustrates the general insight that the scope for all collective policies is limited by the elasticity of market reactions.

\section{On the evolution of European labor market policies}

The slope effects characterized analytically above are arguably relevant to any political mechanism of policy choice. So, they can help understand why labor market policies are more or less intrusive in different countries or periods, and interpret observable inequality, employment, and productivity patterns.

The role of non-labor income and wealth in shaping the welfare effects of labor income redistribution may for example explain why European labor markets became more rigid 
and egalitarian in the 1970s, after the Golden Age of post-war growth had led to accumulation of a large stock of unequally distributed wealth, and made it attractive for a political majority to trade better income security for lower production efficiency. Since the relevant parameters are not as clear in reality as in the mathematical expressions above, the resulting productivity slowdown may have been more pronounced than expected, leading to public debt accumulation. In a more recent phase of European policy evolution, deregulation trends may be related to the market integration, capital mobility, and competition among systems implications illustrated in the model by elastic factor supply of factors other than labor.

It is possible to detect in some interesting cases the stronger deregulation incentives of countries experiencing more elastic market responses to relative policy differences. When the Netherlands found itself the smaller partner of an essentially complete economic and monetary union with Germany, it was logical for it to adopt the wage moderation and deregulation policies implemented by the 1982 Wassenaar agreement. In Germany, the "Agenda 2010" reform framework only took a similar path in the first half of the 2000s (Rinne and Zimmermann, 2012), after the country's reunification, euro adoption, and Eastern enlargement had changed the trade-off between high wages and idle labor on the one hand, and better competitiveness on the other.

The relevance of such structural phenomena can be assessed more formally when comparable cross-country panel data are available, as in the case of euro area countries. Ideally, regression specifications should let policy indicators, driven by exogenous factors, explain labor market outcomes. In practice, it is difficult to measure accurately the wide variety of institutional features that can in reality have the effects illustrated by the model, and available data are neither as accurate nor as plentiful as to allow estimation of the long and likely variable lags with which expected and actual policies affect observable outcomes. A less direct indication of the theoretical mechanism's empirical relevance can be obtained from outcomes patterns that are plausibly driven by past labor policy variation.

The descriptive regressions in Table 1 inspect the relationship between total factor productivity and various other variables of interest. Since productivity is measured as an index with a common basis in 1990, all specifications include country fixed effects and only convey information on within-country dynamic developments. In columns 1 and 2, inequality is significantly and positively related to productivity, both when country effects highlight within country dynamics, and when year effects additionally control for common developments. As discussed above, employment rates are also plausibly influenced by labor market policy: in columns 2 and 3, the coefficient of inequality is barely affected by inclusion of the employment rate; the latter's positive partial association with total productivity may be generated by labor policy variation, or perhaps by labor supply reactions to exogenous productivity variation. To the extent that fixed effects capture the implications of constant or slow-moving country characteristics (such as demographics, ethnic composition, size), and time effects those of trade and technological developments, the relationship between productivity, inequality, and employment traced by these regressors suggests that the mechanisms illustrated by the model are consistent with recent European experience. Stronger productivity growth where inequality and/or employment increase may be driven by changing labor market policy choices along an equality-efficiency frontier sloped like the negative coefficient of inequality as an explanatory variable for productivity, which is significantly negative and remarkably 
Table 1 Descriptive regressions for total factor productivity developments

\begin{tabular}{lcccccccc}
\hline TFP & $\mathbf{( 1 )}$ & $\mathbf{( 2 )}$ & $\mathbf{( 3 )}$ & $\mathbf{( 4 )}$ & $\mathbf{( 5 )}$ & $\mathbf{( 6 )}$ & $\mathbf{( 7 )}$ & $\mathbf{( 8 )}$ \\
\hline Inequality & 0.69 & 0.72 & 0.77 & 0.88 & 0.63 & 0.53 & 0.65 & 0.64 \\
& $(2.87)$ & $(3.27)$ & $(3.30)$ & $(3.98)$ & $(2.75)$ & $(2.42)$ & $(3.33)$ & $(3.10)$ \\
Employment & & 0.79 & & 1.00 & & & 1.06 & 0.91 \\
& & $(5.53)$ & & $(4.42)$ & & & $(8.12)$ & $(4.38)$ \\
Institutional quality & & & & & 0.13 & 0.20 & 0.20 & 0.19 \\
& & & & & $(4.17)$ & $(5.41)$ & $(7.10)$ & $(5.37)$ \\
Country effects & Yes & Yes & Yes & Yes & Yes & Yes & Yes & Yes \\
Year effects & No & No & Yes & Yes & No & Yes & No & Yes \\
\hline
\end{tabular}

Robust t statistics in parentheses. Data sources and definitions: The Conference Board for Total Factor Productivity (1990 = 1 index) and Employment rate (fraction). Eurostat for Inequality, measured as the Gini coefficient (fraction) of equivalized household income. The World Bank for Institutional quality, measured as the average of the six World Bank Governance Indicator (sample mean $=1.31$, std.dev. $=0.39$ ). The sample includes yearly 1996-2011 observations for Austria, Belgium, Finland, France, Germany, Greece, Ireland, Italy, Luxembourg, Netherlands, Portugal, Spain; inequality and institutional quality data are available for roughly half of the years, somewhat unevenly across countries, and are interpolated when missing.

stable also when, in columns 5-8, the regressions control for a general indicator of institutional quality. In these data, countries with better institutions display very significantly lower inequality and higher employment, confirming Sapir's (2006) observations that labor market performance can be unambiguously better or worse in both respects. Such relationships however are weaker or absent when controlling for fixed country effects. This is consistent with a data generation process where each country does face similarly sloped, but differently positioned inequality/employment trade-offs. Institutional improvement, while positively and very significantly associated with economic productivity growth, is weakly enough related to inequality developments to allow the two variables to play distinct explanatory roles.

These empirical associations, while remarkably robust, offer only suggestive evidence, and neglect a large variety of potentially relevant structural factors and theoretical mechanisms. Country-level income inequality can be influenced by international economic integration by wealth inequality and rates of return directly (rather than through policy choices), and productivity is of course related to many factors as well to policy choices along the model's risk and efficiency trade-off. The trade-off itself can vary along dimensions that one might want to try and control. For example, not only public policy but also private contractual arrangements in reality to share risks under asymmetric information. While the stronger verification and enforcement powers of governments may explain why much labor income insurance is publicly organized, the relative efficiency of private financial arrangements varies across countries and over time in ways that, along with international competitiveness concerns, contribute to explain public policy choices (Bertola and Lo Prete, 2013). Inasmuch as household financial market access makes it less necessary to reduce labor income risk, it is not surprising to see that Anglo-Saxon labor markets are much less regulated than Continental European ones, and that both labor market deregulation and financial development trends characterized the period leading to the Great Recession.

\section{Reforms and crises}

The simple model's specific focus on labor market policies can help interpret the large accumulation in that period of negative financial imbalances by peripheral eurozone 
countries, largely mirrored by positive balances in Germany and other core countries. Part of these imbalances reflected investment patterns and capital intensity equalization, which influences pre-tax inequality directly if wealth is more unequally distributed than labor income. A larger portion, however, was accounted for by public and private consumption and housing expenditure patterns which, as discussed in Bertola (2013), plausibly reflected productivity convergence expectations. Labor policy's productivity and risk effects are theoretically and empirically relevant to current accounts (Bertola and Lo Prete, 2012), and may also have played a role. In the aftermath of euro adoption, for countries where economic integration and better organization were expected to increase productivity it might have been sensible to trade some of that efficiency windfall for labor income security. Between 2000 and 2007, total factor productivity and inequality both increased in the core and declined in the periphery of the euro area (Bertola, 2013), and in the data analyzed in Table 1 not only the inequality but also the employment trajectories of peripheral countries are symmetric to those of core countries. While the stronger and more significant relationship between productivity and institutional quality indicators suggests that it would be misleading to focus narrowly on labor market policy developments, the latter may indeed have contributed to accumulation of non-contingent financial imbalances that did not play a risk-sharing role, and became problematic when expectations of institutional and productivity convergence failed to be realized. From this perspective, the crisis should symmetrically trigger labor policy reforms. In terms of the average welfare criteria studied in Section 2 above, for countries that need to improve international competitiveness and repay ex-post excessive debt it would be optimal to forego some security, and increase productivity. Implementation of such structural reforms is difficult, however, for at least two conceptually different reasons.

The first is that reforms can damage specific individuals at the same time as they improve average welfare. As discussed in Section 3, the pros and cons of labor market policies differ across individuals who at a point in time happen to be differently entitled to the simple model economy's non-labor income. In more complex models, labor market policy may also benefit specific groups of workers or employers regardless of whether it improves the level of production or smooths out the riskiness of its distribution. Individuals who expect to earn more are obviously less inclined to favor redistribution: as in Agell (2002), the equilibrium intensity of distortions and redistribution may then depend on the political power of individuals who face different trade-offs between expected income losses and better income smoothness. Allowing for such heterogeneity would of course open the way to even more direct "rent seeking" tensions, such as struggles over the size of the individual lump-sum transfers that in the simple model are as homogeneous across workers as their ex ante characteristics. Heterogeneity may when reforms are considered relate to individual labor market status, as "outsiders" who find themselves shut out of protected employment opportunities favor deregulation more strongly than incumbent "insiders." From the economic point of view, reforms that clearly improve average welfare could eliminate such rent-preservation obstacles using ex-ante transfers to compensate losers, or introducing flexibility along margins that preserve status-quo rents (like the multi-tiered wage arrangements studied by e.g. Fehr and Kirchsteiger, 1994). In practice, the negotiation and implementation of such policy packages faces political problems of incomplete and asymmetric information that are similar to those that make labor income risk difficult to insure. 
There is no room for such rent-preservation motives and possible rent-sharing reform solutions in the simple economy of Section 2, where only ex-post shocks are heterogeneous across workers. But that single-period model's assumption that labor market increases productivity only if workers perform costly ex-ante actions illustrates the second difficult issue facing labor market reforms, namely the need to establish credibility. In the model, what matters for labor allocation and productivity is the policy configuration that is expected to determine ex-post redistribution shape incomes at the time when investment choices are made. In reality, the lag between ex-ante choices and their effects can be long. Changes of life- and career-shaping institutions (in education, labor market, and pensions) modify the conditions in which choices made a long time ago have effects, and cannot quickly influence behavior that will have effects in the future. Hence, reforms that may be reversed need not strengthen incentives to make choices that increase the economy's overall productivity.

Credibility is as necessary for labor reforms as for monetary or fiscal policies, and similarly elusive at times of political and economic turmoil. Just like falsified expectations of productivity growth may have contributed to the onset of the current European crisis, uncertainty surrounding reform processes not only reduces the welfare of risk averse individuals, but also hinders adjustment in the aftermath of the crisis. If the risk aversion that the model takes to be constant is in reality decreasing, deregulation in crisis times has more negative welfare implications, and weaker effects on incentives for effort or investment choices that entail higher risk at the same time as they increase the economy's productivity. If deregulation is perceived to magnify individual income risk without suitable payoffs in terms of income growth expectations, reforms will be unpopular and likely to be reversed. To prevent self-fulfilling low-credibility equilibria, reforms paths should be sequenced so as to prevent distributional issues from damaging their political sustainability. To this end, it appears useful to target not only labor policies but also the broad variety of institutional and policy aspects that position countries at different points along the regressions shown in Table 1. In many European countries, including those that are doing well in the current crisis, retail, business, and financial services are sheltered from international as well as domestic competition. Reforms aimed at transparent, well regulated, corruption-free product markets and financial markets would make it easier to undertake more technically and politically difficult reforms of labor and social policies that, while partly explained by rent-preservation motives, also address the need to protect labor income from product and financial market imperfections.

\section{Conclusion}

As long as insurance markets and policies remain imperfect, it is moot to blame low production efficiency on labor market policies that also stabilize labor incomes. Reforms of such policies should be motivated by structural changes of the trade-off between their pros and cons. In general, demographic trends, migration flows, and changes of family structure can influence support for pay-as-you-go pension scheme, or for labor market rigidities that make it difficult for youth to find employment at the same time as they protect their parents' income. In Europe specifically, labor market reform pressure has arguably also come from international economic integration, other technological and organizational innovations, from financial development that made it appear less necessary to interfere with laissez faire labor market outcomes in order to smooth temporary 
income fluctuations, and from crisis shocks to both the desirability of labor income support, and the affordability of production efficiency losses.

The economic aspects illustrated in this paper can help understand the sources and consequences of labor market reforms of the 1980s (in the United Kingdom and in the Netherlands), of the 1990s (in Sweden's post-financial crisis experience), of the pre-crisis 2000s (in Germany's reforms, and in other countries' similar introduction of flexibility at the margin). The design, implementation, and sustainability of reform processes, of course, also depend on political aspects. Since the consequences of reforms are very difficult to predict, "there is no need" objections easily prevail when things are going well, and radical reforms are more likely to be implemented when crises support "there is no alternative" arguments. But the infrequent reforms that we do observe in reality also reflect such specific political factors as Mrs. Thatcher's stubborn personality, or the willingness of Mr. Schroeder's left-of-center government to sacrifice its own popularity. And just like political processes do not always channel crises into reforms, so they need not successfully steer reform processes along a suitably credible path between defeatism and complacency. A forward-looking perspective can support an economically sensible, politically sustainable, and suitably credible reform path, which is however always threatened by the "all is lost anyway" or "change is too risky" political sentiments that crises also tend to produce.

\section{Competing interests}

The IZA Journal of Labor Policy is committed to the IZA Guiding Principles of Research Integrity. The author declares that he has observed these principles.

Authors' information

The author is Professor of Economics at EDHEC Business School and research fellow at CEPR, IfW, CFS, CESifo, on extended leave as Professore Ordinario, Università di Torino.

\section{Acknowledgements}

This paper benefits from useful comments received at the IZA "Labor Market Reforms during the Great Recession: Challenges and Opportunities" workshop (Brussels October 10-11 2013), from a referee, and from the editor on the working paper version (CEPR DP 9707, CESifo wp 4450).

Responsible editor: Juan F Jimeno.

Received: 17 October 2013 Accepted: 29 January 2014

Published: 01 Mar 2014

\section{References}

Agell J (2002) On the determinants of labor market institutions: rent seeking vs. social insurance. German Econ, Rev: $107-135$

Andersen TM (2010) Incentive and insurance effects of tax financed unemployment insurance. CEPR Discussion Papers No. 8025

Barkbu B, Rahman J, Valdés R, et al (2012) Fostering growth in europe now. IMF Staff Discussion Note SDN/12/07

Bertola G (2004) A pure theory of job security and labor income risk. Rev Econ Stud 71-1: 43-61

Bertola, G (2013) Policy coordination, convergence, and the rise and crisis of EMU imbalances. European Economy Economic Papers 490. European Commission DG Economic and Financial Affairs, Brussels

Bertola G, Lo Prete A (2012) Labor market reforms, finance, and the current account. Working paper

Bertola, G, Lo Prete A (2013) Finance, governments, and trade. Rev World Econ 149: 273-294

Fehr E, Kirchsteiger G (1994) Insider power, wage discrimination and fairness. Econ J 104: 571-583

Mirrlees JA (1971) An exploration in the theory of optimum income taxation. Rev Econ Stud 38: 175-208

Mulligan C (2012) Uncertainty, redistribution, and the labor market. Working paper

Okun AM (1975) Equality and efficiency: the big tradeoff. Brookings Institution Press, Washington, DC

Rinne U, Zimmermann KF (2012) Another economic miracle? The German labor market and the great recession. IZA J Labor Policy: 1-21

Sapir A (2006) Globalization and the reform of European social models. J Common Market Stud 44-2: 369-390

Sinn H-W (1996) Social insurance, incentives and risk taking. Int Tax Public Finance 3: 259-280

10.1186/2193-9004-3-5

Cite this article as: Bertola: Labor market policies and European crises. IZA Journal of Labor Policy 2014, 3:5 